\title{
Rethinking Education and Training in Vietnam Rural Areas*
}

\author{
Pham Do Nhat Tien \\ National Institute of Education Management, \\ Hanoi, Vietnam
}

\author{
Tran Thi Thai Ha \\ Vietnam Institute of Educational Sciences, \\ Hanoi, Vietnam
}

\begin{abstract}
Education in Vietnam is currently dominated by the "more of the same" thinking, equating learners in all geographical areas, with an urban bias and supply-driven tendency. Accordingly, there is no clear orientation in the development of education and training in rural areas. Such a mindset is a barrier in the development of rural human resources to effectively meet the requirements of economic restructuring and new rural construction. Therefore, it is necessary to rethink the development of general education, technical and vocational education and training (TVET), and continuing education in rural areas to facilitate and encourage students to pursue and develop agriculture, engage in rural innovation, have self-confidence in career development, and get comfortable and happy life on their homeland.
\end{abstract}

Keywords: rethinking education, education in rural areas, general education, technical and vocational education and training (TVET), continuing education, new rural area

\section{Introduction}

Until now, Vietnam has implemented the "doi moi" (renovation) reforms for nearly 30 years, in an effort to develop a socialist-oriented market economy. The major achievement of this renovation process is to transform Vietnam from a low-income to a middle-income country.

During this economic growth, agriculture, rural areas, and farmers have played an exceptionally important role as a platform for industrialization. There have been great and positive changes in the agricultural production, rural settings, and farmers' lives. However, in comparison with economic growth and social progress of the country, agriculture, rural areas, and farmers have been suffering from an unfair position. Agriculture has never been invested adequately, and consequently, Vietnam's agriculture is still basically a processing one, mainly characterized by human labor and natural resources exploitation. Rural areas are losing their attractiveness when adults get bored with fields, and young people are quitting farming production and leaving their homelands. As for farmers, although they account for $70 \%$ of the population, they benefited only a small share of achievements from economic growth and international integration. Poverty, diseases, and dropouts remain persistent social ills clinging farmers' lives.

The main cause of the above-mentioned situation is the inadequate awareness of the status and role of

\footnotetext{
${ }^{*}$ This article study was conducted within the framework of the research project VI2.3-2011.12 funded by the National Foundation for Science and Technology Development (NAFOSTED), and was presented in its earlier version as a keynote address at the international workshop on "Education for Rural Areas in the Process of Economic Structural Transformation", November 6, 2014, Hanoi, Vietnam.

Pham Do Nhat Tien, D.Sc., senior researcher, Scientific Council, National Institute of Education Management.

Tran Thi Thai Ha, Ph.D., director, Manpower Training Needs Analysis and Forecast Center, Vietnam Institute of Educational Sciences.
} 
agriculture, rural areas, and farmers, as indicated in the Central Communist Party's Resolution No.7 about agriculture, rural areas, and farmers (Vietnam Communist Party, 2008). Properly speaking, in the process of enhancing industrialization and modernization, aiming to basically become a modern-oriented industrialized country by 2020, the development thinking of Vietnam decision-makers tends to emphasize the role of industry and urban areas while overlooking that of agriculture and rural areas.

Such biased thinking has also been implicit in education development for nearly 30 years of renovation. Education and training are primarily seen through the lens of urban dwellers. Curriculum development, textbook compilation, assessment, and career orientation are mainly targeted at a model of learners in urban settings. Research on educational sciences, particularly research on the improvement of education quality, is primarily focused on the elements of the education system, such as schools, teachers, learners, curricula, educational management, and educational finance. Educational research by demographic region, particularly in rural areas, has not yet been paid adequate attention. Although the population at school age in rural areas accounts for around $70 \%$ of that of the whole country, the "more of the same" mindset still prevails in the organization and operation of education and training with an urban bias.

In a study jointly conducted by the United Nations Educational, Scientific and Cultural Organization (UNESCO) and Food and Agriculture Organization (FAO) of the United Nations on education for rural development, a key message is that "more of the same" will not solve the education problem in rural areas, particularly in the context of globalization (Atchoarena \& Gasperini, 2003). As such, we need to rethink, that is to clarify the diverse needs of rural learners, and then adequately handle the demand and supply of rural education so as to effectively respond to human resources development required by economic restructuring and implementation of the so-called Tam Nong policy (Agricultural Policies Triangle, i.e., agriculture, farmer, and rural development).

\section{General Education in Rural Areas}

If general education is viewed under its four dimensions, i.e., access, quality, efficiency, and equity, then it can be said Vietnam has made impressive progress in access development, but remained weak in improving quality, efficiency, and equity. These shortcomings persist chiefly and significantly in rural education.

Recently, in a research project entitled "Solutions for Improving the Quality of Rural Education in the Period of Economic Structure Transformation", Tran Thi (2013) made a comprehensive analysis to identify the factors that influence the quality of education in rural areas under the context of economic restructuring. Based on that analysis, a cluster of solutions, of which the solution about educational management is seen as a breakthrough for improving the quality of education in rural areas, have been proposed.

It should be clarified as to why the solution about management renovation is considered as a breakthrough. So far, this statement has often been raised in many proposals about solutions for education renovation, and therefore it seems to become clichés and lose its particular interest. However, for education in rural areas, this solution is really crucial, because thinking about rural education development has lagged far behind the realities of agricultural and rural development in the context of market economy and international integration.

As noted earlier, the thinking about education development in Vietnam has been "more of the same". A common goal for general education has been defined in the Education Law. Accordingly, schools across the whole country implement a unified curriculum with the same textbooks. Obviously, there are some topics and 
units on agriculture, rural areas, and farmers, but with an old thinking about agriculture associated with farming and animal husbandry; about rural areas associated with fields and ponds; and about farmers associated with miserable lives experienced by such famous characters as Sister Dau or Brother Ba in Vietnamese works of classical literature. Above all, the approach in terms of curriculum, contents, and teaching and learning methods is clearly biased in favor of urban learners. Meanwhile, rural students who make up a large proportion of students in schools, realized that the actual rural settings, new agricultural life, and the different needs in knowledge, skills, and attitudes that rural children are expected to know and be able to do, have been mentioned during lesson hours only in a superficial manner.

Despite the fact that there are common requirements for all pupils in core subject teaching and learning, but if education in rural areas neither has a close relationship with the surrounding environment of a child, nor addresses essential and different needs in his/her rural life, then this education will make him/her bored and ultimately drop out of school. Eventually, this will contribute to the driving force which pushes him/her from the village to pull him/her to the city.

As such, it is crucial to translate overall objectives of general education into specific objectives of education in rural areas. In other words, general education in rural areas should have a clear orientation that encourages students to pursue and develop agriculture, nurtures their ambition about rural innovation, and enhances their confidence in career development and in building a happy life on their homeland.

This orientation should be specified right now in the process of renovating the general education curriculum after 2015. This curriculum renovation is following a competency-based approach, according to which the post-2015 curriculum of general education will aim at nurturing and developing the generic core competencies for students in school and in life, including: (a) competencies for self-development (self-learning, problem-solving, critical thinking, creativity and innovation, and self-management); (b) competencies in social relations (communication and cooperation); and (c) competencies in using tools interactively (language, media, information, communications, and technology).

The elaboration of these competencies is currently being undertaken in the direction of clarifying the learning outcomes in terms of knowledge, skills, and attitudes for each field of study/subjects as well as methods of teaching and learning. It is planned to have a flexible curriculum, according to which besides the core content, there will be flexible contents adapted to characteristics and requirements of local socio-economic development. Many sets of textbooks will be also compiled. However, it has not yet been clear so far as to how the post-2015 curriculum of general education will be designed for rural students so that they will have necessary and appropriate competencies to really become future owners of the new countryside.

This probably challenges curriculum developers and administrators when they are still overloaded with the development of the post-2015 curriculum and textbook renovation scheme. Nevertheless, this issue has to be mentioned inevitably at this point in time if the gap in development thinking is to be narrowed so that education becomes a major tool for shaping and implementing the objectives of agricultural development, rural renovation, and improvement of the material and spiritual life of the rural population in the context of economic restructuring and international integration. Additionally, for the following reasons, this is not an entirely new issue that remains unsolved:

1. Education in Vietnam had previously achieved considerable success in implementing the motto of "learning associated with practicing", particularly in rural areas, exemplified by the school model in Bac Ly commune during the 1960s; 
2. There have been a lot of successful international practices in developing education for rural areas, such as school garden model of Cuba and Escuela Nueva model of Colombia that is currently being piloted in Vietnam;

3. The nature of education in rural areas is that teaching and learning should be contextualized, bringing into play life experiences of rural students, making full use of available natural and human resources of local community, and responding to practical needs of rural students on the basis of investigations and surveys. Viewed as such, Vietnam education already had some experiences in the deployment of teaching methods according to project-based learning and contextual learning during the on-going process of renovating teaching and learning methods. The question is just how to properly adopt these methods for education in rural areas so that rural settings, agricultural activities, and practical experiences of learners are mobilized to not only develop the basic knowledge and skills, but also increase interest in learning, joy to contribute, and strengthen desirable skills, such as critical thinking, problem-solving, teamwork, learning how to learn, etc..

Obviously, learning from practices and international experiences as well as implementation of new learning models is only part of the solution. There are still many issues to be considered, such as in-service teacher training, school autonomy enhancement, community participation, etc.. However, the fundamental factors are now available and ready for a renovation of general education in rural areas, along with the development of the post-2015 curriculum, provided that decision-makers genuinely rethink about the status, role, and orientation of educational development in rural areas in the context of growth model renovation and international integration.

\section{Technical and Vocational Education and Training (TVET) in Rural Areas}

TVET plays a particularly important role in the development of human resources in developing countries. As Vietnam is accelerating its industrialization and modernization, TVET is the main tool to provide qualified human resources at the elementary and intermediary levels, which constitute the largest share of manpower structure in the process of economic restructuring. Nonetheless, viewed from the four-dimensional approach-access, quality, efficiency, and equity-TVET is actually one of the bottlenecks of Vietnam on its way to enhance its competitiveness. And like general education, such shortcomings are mainly concentrated in rural areas.

There are many causes leading to this situation. However, the major cause is a domination of biased thinking in TVET that attaches greater importance to technical and vocational skills in industry and services than to those in agriculture. Moreover, even in agricultural disciplines, technical and vocational skills that are provided to learners fail to adapt with changes in the rural labor market which is much different from itself in the past.

Some 30 years of renovation with the development of agriculture through expanding market, accelerating mechanization, increasing the use of advanced science and technology, liberating trade, and integrating in global market have resulted in a significant change in rural labor structure with the formation of a new labor market, with new skills requirements, in which agricultural labor has been declining while non-agricultural employment increased. Rural people today do not live only by agriculture but also have significant income from off-farm activities, such as running a business, clothing, hairdressing, restaurants, seasonal working, minor repair, travel services, including labor export, etc..

Hence, TVET in rural areas needs to be a multi-purpose activity so as to meet the diverse needs of rural youth in finding employment and job creation associated with the shift in employment structure and rural labor. 
TVET in rural areas should be demand-driven, focusing on demand for skills that are required by the current rural labor market. However, in this regard, a recent report by the World Bank (2012) indicated that Vietnam TVET is still mostly supply-driven. The promotion of a demand-driven approach remains weak, and this shortcoming should be overcome quickly.

Then, what skills are in demand that TVET should provide for rural youth, so that they keep attach with their homeland? This is a crucial question, because TVET plays a major role in retaining youth to agriculture and rural areas, while general education is more likely to push rural youth to cities (Atchoarena \& Gasperini, 2003).

However, so far, Vietnam TVET has not had a significant research study to answer this question. Although there may be many studies on technical and vocational skills, they primarily focus on different occupations and qualifications with poor attention to rural areas. Therefore, to address the skill gap in rural areas in order to really improve quality, efficiency, and equity in TVET, it is necessary to conduct surveys and/or investigations at the local level to clarify the demand for skills in the new rural labor market and to identify the issue of supply and demand for skills in rural areas.

\section{Continuing Education in Rural Areas}

From the late 1990s, continuing education in Vietnam has developed towards promoting lifelong learning, and building a learning society. Significant achievements have been obtained, including the expansion of educational networks from formal education to continuing education throughout the country, the diversification of types of schools and modes of delivery, the rise in educational attainment, the improvement of linkage and articulation among training levels, and the progress in social equity in education.

However, as well as general education, the major achievement of continuing education is in access development. Weaknesses in quality, efficiency, and equity remain a major concern in continuing education.

Particularly in rural areas, the approach in continuing education development has been hither to supply-driven, focusing chiefly in creating learning opportunities for dropouts and adults. Therefore, the main tasks are illiteracy eradication and development of continuing education centers and community learning centers. A specific direction for continuing education in rural areas has not yet been addressed.

It should be noted that in the context of complex economic life of today's society under the impact of market economy and international integration, continuing education in rural areas, as was confirmed at international conferences on adult education (for example, UNESCO, 2008), is the main tool for farmers to make use of opportunities and cope with challenges in the relationships between agricultural development and economic sustainability and ecology, employment and income, cooperation and competition, practices and scientific advances, knowledge and skills, environmental pollution and climate change, etc..

Unfortunately, despite numerous rhetoric about continuing education in Vietnam, the status and role of continuing education in socio-economic development in general, and in agricultural and rural development in particular, have never received proper attention. Though on par with formal education as stipulated in the Education Law, continuing education is in fact overlooked, even implicitly regarded either as a second-class education for illiterates, unlucky people, and disadvantaged children, or as a shelter for "bad learners", a place to "buy" easily a certificate or degree necessary for promotion in the career ladder, and a legitimate way for teachers to increase their income. Despite the fact that community learning centers have remarkably been developing in recent years in rural areas, but basically it is chiefly a movement-led development, less 
substantial in meeting the demand for new skills that farmers need to cope successfully with the demands and challenges of a transforming agriculture with new technologies, new markets, new products, and new business environment. This further explains why farmers have poor motivation for farming, and why youth flock to cities while staying people become victims of various issues, such as falling price in good harvests, coercion of businessmen, tricks of foreign traders, environmental pollution, and animal diseases.

A typical example for the lack of direction in the development of continuing education in rural areas is the implementation of the Vocational Training Scheme for Rural Workers to 2020. This is a large-scale scheme for vocational training in rural areas with the biggest investment budget so far in vocational training. It can also be seen as a scheme for the development of continuing TVET in rural areas. Duplicating the inadequacies of TVET, this scheme is implemented with a supply-oriented focus. Therefore, its main beneficiaries are the vocational training institutions instead of rural workers. A review of four-year implementation (2010-2013) by experts indicated that apart from the achievements, vocational training for rural workers still faced a fundamental shortcoming that was a lack of orientation in the improvement of rural labor market, so that farmers who completed vocational training can earn a job and have stable income (Mai, 2013). This review also stresses that continuing vocational training for rural workers needs to be associated with the process of building new rural areas, agricultural modernization, and labor shift in the direction of creating new agricultural and non-agricultural jobs in collaboration with companies, businesses, and cooperatives.

Of course, continuing education in rural areas is not just equipping and updating vocational knowledge and skills for rural workers. As:

A key component of a holistic and comprehensive system of lifelong learning and education which integrates formal, non-formal and informal learning and which addresses, explicitly or implicitly, both youth and adult learners, ... about developing self-reliant, autonomous individuals, building and rebuilding their lives in complex and rapidly changing cultures, societies and economies — at work, in the family and in community and social life. (UNESCO, 2010, p. 11)

Continuing education in rural areas should be considered as a large and multi-purpose field. It is the successor, supplement, and continuation of both general education and TVET in order to update and improve knowledge and skills for workers during their skills development journey throughout life and in every context.

As such, it is necessary to rethink the status and role of continuing education in rural areas, so that it has a clear orientation in encouraging rural people, youth, and adults, to attach their life to agriculture and rural areas, to be self-confident and autonomous in developing their careers in rural settings, to advance in employment and life, to make use of the opportunities in building new rural areas, and to respond successfully to the challenges of rural labor restructuring.

\section{Conclusions}

This paper would like to clarify the problem of rural education development from the staring point related to the thinking of education and training in Vietnam rural areas. Some conclusions can be made as follows:

1. So far, in the development of education in Vietnam, there is not yet a specific thinking for the orientation of education and training development in rural areas. The current dominant thinking is "more of the same" that equates all learners, while the implementation of curricula, contents, and teaching and learning methods is practically driven by an urban bias;

2. Such thinking of education and training in rural areas has lagged far behind the actual development of agriculture and rural areas today. It can even become a barrier in the development process when the economic 
thinking has significantly changed towards the renovation of growth model along with the implementation of the Agricultural Policies Triangle and the new rural construction;

3. A rethinking of education and training in rural areas is imperative. Namely, education and training in rural areas should have a specific orientation in its mission and goals, that is to contribute practically to the development and prosperity of rural areas, including food security, health, employment, income, personal development, environmental protection, resource management, identity preservation, and community cohesion;

4. Such rethinking leads to new requirements for general education, TVET, and continuing education in rural areas. The basic feature of these requirements is the shift of rural education and training from supply-driven to demand-driven, in order to ensure that rural learners acquire relevant knowledge, skills, and competencies to be able to develop confidently their career in their homeland, and to contribute to the development of agriculture associated with industry and services in the process of building new rural areas;

5. In the process of identifying what skills are in demand today for rural workers, it is beneficial to refer to the findings of the 2014 Vietnam Development Report (World Bank, 2013) which seeks to offer a strategic skills development for Vietnam in its way of preparing the workforce for a modern market economy. Accordingly, a holistic skills development strategy for Vietnam should consist of three steps: First, promoting school readiness through early childhood development with the focus on cognitive skills formation; second, building the cognitive and behavioral foundation skills in general education; and, third, building job-relevant technical skills in TVET, higher education, and continuing education, through a more connected system. Obviously, from the viewpoint of developing a demand-led rural education and training, the above-mentioned three-step model in skill development should be used as a platform for further identification of skills that rural learners need to acquire and master respectively in general education, TVET, and continuing education;

6. Education development in rural areas in line with the above-mentioned orientation could not be implemented successfully without a multi-sectoral and multi-disciplinary approach in agricultural modernization and building new rural areas. The lack of a harmonized strategy jointly developed by multiple sectors, different levels of administration, and various social forces in agricultural and rural development will likely lead to a consequence that the more educated young people are, the more likely they are to migrate to urban cities for better living, employment, and advancement opportunities. The reality in Vietnam rural space is currently alarming on brain drain and youth migration to urban areas, leaving behind deserted villages with a distorted social structure in gender, age, qualifications, and labor. Therefore, changing the thinking on education development in rural areas requires necessarily a behavioral change in not just the education sector but also all other related sectors in the process of implementing the Agricultural Policies Triangle and building the new rural areas.

\section{References}

Atchoarena, D., \& Gasperini, L. (Eds.). (2003). Education for rural development: Towards new policy responses (A joint study conducted by FAO and UNESCO). Rome, Italy: FAO; Paris, France: UNESCO.

Mai, P. (2013, December 13). Vocational training for rural workers after three years of implementation. Vietnam Communist Party Online Newspaper. Retrieved from http://dangcongsan.vn/cpv/Modules/News/NewsDetail.aspx?co_id=28340744 $\& \mathrm{cn} \_\mathrm{id}=625954$ (In Vietnamese)

Tran Thi, T. H. (2013, August 24). Solutions for improving the quality of rural education in the period of economic structure transformation. Final report presented to the Review Council at the National Institute of Educational Sciences. (In Vietnamese) 
United Nations Educational, Scientific and Cultural Organization (UNESCO). (2008, October 6-8). Asian statement on building equitable and sustainable societies in Asia and the Pacific. Proceedings of The CONFITEA VI Preparatory Conference in Asia and the Pacific, Seoul, Republic of Korea.

UNESCO. (2010). Belem framework for action. Proceedings of The Sixth International Conference on Adult Education. Hamburg, Germany: UNESCO Institute for Lifelong Learning.

Vietnam Communist Party. (2008). Resolution of the 7th session of the Party Central Committee, 10th tenure. Hanoi, Vietnam: National Politics Publishing House.

World Bank. (2012). Vietnam workforce development: SABER country report. Washington, D.C.: World Bank Group. Retrieved from http://documents.worldbank.org/curated/en/2012/01/20142453/saber-workforce-development-country-report-vietnam2012

World Bank. (2013). Vietnam development report 2014. Hanoi, Vietnam: Vietnam Development Information Centre. 